The effect of languagefocused professional development on the knowledge and behaviour of preschool practitioners

\author{
Lauren Kidd \\ University of Liverpool, UK
}

\title{
Caroline Rowland
}

University of Liverpool, UK; Max Planck Institute for

Psycholinguistics, The Netherlands

\begin{abstract}
The purpose of this project was to investigate the effectiveness of a language-focused professional development programme on the knowledge and behaviour of preschool practitioners (sometimes called early years practitioners) in the UK. In Study I we determined whether the training received by practitioners is effective in improving their knowledge of how to support children's language and communicative development. In Study 2 we tested whether trained practitioners, and practitioners from centres with embedded Language Champions, were able to implement the techniques they had been taught. For this, we video-recorded practitioners interacting, one to one, with 2- and 3-4-year-old children in their centres. We conclude that (I) practitioners retain the knowledge they have been taught, both about how children learn and about how to promote this learning, and that (2), in some respects, this knowledge translates well into practice; practitioners in centres with embedded Language Champions and trained practitioners used language-enriching behaviours when interacting with children more often than did untrained practitioners. We discuss how the translation of some techniques into overt behaviour could be made more effective.
\end{abstract}

\section{Corresponding author:}

Caroline Rowland, Max Planck Institute for Psycholinguistics, Wundtlaan I, Nijmegen 6525 XD, The Netherlands.

Email: Caroline.Rowland@mpi.nl 


\section{Keywords}

Adult/child talk, childcare training programmes, early intervention, language and communication, language development

Children's literacy development is very much dependent on their early language development. Children who start school with good language skills have a better chance of achieving high levels of literacy, of succeeding in school, of accessing higher education and of being economically successful in adulthood (Waldfogel and Washbrook, 2010). Children's early phonological abilities are essential for their ability to decode text, and their broader oral language skills, such as vocabulary and grammar, are important components of reading comprehension (Bishop and Snowling, 2004). Conversely, persistent communication and language difficulties that are not addressed by suitable intervention and support often lead to difficulties with schooling and reduced life chances (Clegg et al., 1999). Thus, improving children's language and communication before they reach school can be one of the most effective things we can do to boost their ability to succeed in later life (Blanden, 2006).

Crucially, the child's early environment has a significant impact on their language and emergent literacy skills. The quantity and quality of the linguistic input that children receive from their parents predict a substantial amount of the variance we see in the speed of children's vocabulary learning in the preschool years (e.g. Rowe, 2012). Similarly, children who attend good quality day care, with practitioners trained in how to provide them with multiple language learning opportunities, show significantly greater gains in language achievement (Burchinal et al., 2011; Pianta et al., 2002).

Thus, many governments have developed best practice standards to educate practitioners about the importance of early language development and teach them behaviours to implement in the classroom to promote it. In the UK, the Bercow (2008) report drew attention, nationally, to the importance of addressing children's speech, language and communication needs and, ever since, language development has formed a central part of professional development training for preschool practitioners. Similar initiatives have been implemented in other countries (e.g. U.S. Department of Education, 2001).

However, we know from public health initiatives on obesity reduction and smoking cessation that it is difficult to trigger long-term changes in people's behaviour (Marteau and Lerman, 2001; Walls et al., 2009). This problem is just as relevant to training initiatives designed to influence the behaviour of 
professionals in their working lives as it is to those designed to influence public health (Eccles et al., 2012). Thus, it is important to evaluate whether language-focused training programmes deliver practitioners who are not only better informed about language development, but are willing and able to implement language-promoting techniques in their own preschool centres.

Unfortunately, evidence on the effectiveness of such training is still emerging (Hillman and Williams, 2015) and has produced mixed results (Markussen-Brown et al., 2017). In addition, much of the literature evaluates researcher-created interventions rather than professional development training provided by state or private providers (Piasta et al., 2017), and there is some evidence that the latter may be less effective (Markussen-Brown et al., 2017). Similarly, most research studies only evaluate practitioner behaviour on a global, often classroom-based level, rather than at the level of the individual child, even though most training programmes focus on providing advice about how to interact with individual children. There is also significantly more work based in US and Canadian schools than in other countries, many of which have very different preschool education set-ups.

In this project, we evaluated how a language-focused professional development programme, devised in the UK by one Local Authority's School Readiness Team, was implemented by preschool practitioners. We assessed its impact both on practitioner knowledge about how to promote language development, and on how effectively practitioners use language-promoting behaviours when interacting with individual children. Below, we outline the literature that details which types of caregiver behaviour are effective in boosting children's language and describe how this evidence has been implemented in training programmes, before summarizing the aims of the study.

\section{How adult communicative behaviour influences child language development}

Language-focused professional development programmes are firmly rooted in literature showing that caregiver behaviour has a critical effect on children's language acquisition (though see Lieven, 1994, for evidence of different childcare practices in non-Westernized cultures). First, at the most basic level, adults provide children with a language model; information about the phonemes and words of their language, how to combine words into grammatical sentences, and how to use sentences appropriately in discourse. The quantity (e.g. numbers of words and sentences produced) and diversity (e.g. number of different word types) of the language produced by both parents and practitioners has a substantial effect on how quickly children 
acquire vocabulary and grammar (Bornstein et al., 1998; Cartmill et al., 2013; Demir-Vegter et al., 2014; Dickinson and Porche, 2011; Hart and Risley, 1995; Hoff and Naigles, 2002; Hurtado et al., 2008; Huttenlocher et al., $2002,2010)$. The numbers of descriptive statements and open questions (i.e. questions that elicit speech from children and encourage conversation) used by parents also positively influence children's language development (see e.g. Hoff-Ginsberg, 1985, 1986; Hoff-Ginsberg and Shatz, 1982). Conversely, talk that is focused on directing children's behaviour or their attentional focus has a negative effect (Barnes et al., 1983; Dunham et al., 1993; Newport et al., 1977; Tomasello and Farrar, 1986), although directives that respond to or encourage the child's continuing attention are positively correlated with language growth (Akhtar, 1999; Vibbert and Bornstein, 1989).

Second, adults encourage language growth by engaging in languagefocused activities with children (see Hoff, 2006 for a review). For example, shared book-reading provides adults with opportunities to model language; they tend to produce more speech overall, to use structurally more complex and lexically more diverse language, and to use more questions, more descriptive language (e.g. object-labelling) and fewer directives during shared reading (Choi, 2000; Goddard et al., 1985; Hoff, 2003; Hoff-Ginsberg, 1991; Jones and Adamson, 1987; Snow et al., 1976; Weizman and Snow, 2001). In fact, the effect of shared reading is so substantial that variability in the amount of reading in the home is a significant predictor of children's vocabulary development, even when other factors such as socio-economic status are taken into account (Payne et al., 1994; Scarborough and Dobrich, 1994). Nursery rhymes and songs that put a clear emphasis on the form of words (e.g. alliteration) also boost children's phonological awareness, a precursor skill for later literacy (Bryant et al., 1989; Dunst et al., 2011).

Third, adults influence children's language development by tailoring their interactions to the child's developmental level. For example, Rowe (2012) assessed age-related changes in the contribution of input quantity and quality to vocabulary growth, looking at the effects of input addressed to children aged 18, 30 and 42 months of age on their vocabulary 12 months later. Younger children (30 months old) seemed to benefit most from repetition, when caregivers repeat a small number of key words. However, at 42 months, lexical diversity (total number of different word types) and sophistication (total number of rare words) were the strongest predictors of vocabulary development. By 54 months, the amount of decontextualized talk in the input (explanations, talk about pretense, narratives) took over as the strongest predictor. This progression makes sense when seen in light of the acquisition 
tasks facing children at different ages. The youngest children know fewer words, so frequent exposure to a small number of words will be effective. However, later in learning, high frequency words will already have been learnt. Thus, exposure to a larger variety of low frequency words becomes more important. Even later, the introduction of decontextualized language introduces children to a new, different set of (infrequent) words.

Fourth, adults can promote children's language by engaging in a responsive style of interaction in conversations. Children whose caregivers respond more frequently to their early vocalizations reach the 50-word milestone at younger ages (Tamis-LeMonda et al., 1996, 1998). Contingent talk (a style of communication in which the adult talks about what is in the infant's current focus of attention) seems particularly effective; language learning is quicker if adults talk about objects or activities that children are already attending to (see McGillion et al., 2013). However, parental responsiveness overall (e.g. responsiveness to vocalizations, play and focus of attention) is in itself a good predictor of how quickly children achieve the main language milestones (TamisLeMonda et al., 2001). More specifically, adults can influence language development by providing feedback on the accuracy of children's own utterances. Although adults do not tend to correct their children's grammar (see Rowland, 2014, for a review), they do provide them with evidence about well-formedness via recasts and expansions, which model an adult-like way of conveying information. Expansions provide additional syntactic and semantic information (e.g. if the child has just said 'the dog', the adult may say 'yes, the dog is barking') and recasts of children's errors are effective at highlighting the correct form without overt correction (e.g. if the child has just said 'trucks big' the adult may say 'yes, the trucks are big'). Both have been shown to promote language development in typically developing children (Nelson et al., 1973; Newport et al., 1977) and in interventions for children with language difficulties (Cleave et al., 2015). In sum, in many different ways, adults mould and shape the nature, speed and success of child language development in the preschool years.

\section{Language-promoting behaviours in practitioner training programmes}

Although some language-focused training programmes focus on how to explicitly teach vocabulary in a lesson-style format (e.g. Phillips et al., 2017), most train practitioners to use the incidental language-promoting strategies summarized above in naturalistic, everyday situations, such as free play, activity-focused play and mealtimes (see online Appendices I, II and III 
for an overview of the type of training offered to practitioners in the UK). The research behind this guidance can be traced back to the literature above and to pedagogical approaches within the education literature.

For example, as detailed in online Appendix II, practitioners are trained to model language in the classroom: to use more and a greater variety of speech, to use particularly useful types of oral language (e.g. comments, open questions), and to provide children with information about the range of words and sentence structures available to them by repeating target words (Beck et al., 2013; Wasik and Hindman, 2014) or using sophisticated language (Dickinson and Porche, 2011). Practitioners are taught to design preschool environments so as to promote language and literacy development, and to engage in activities, such as dialogic reading, songs and nursery rhymes, which facilitate language (see e.g. Lonigan et al., 1999). They are taught how to tailor their interactions with children so that they use language that is appropriate to the child's developmental level; an idea formalized in the pedagogical approach called individualized instruction, which teaches that activities, methods and instruction should be modified, online, to meet the needs of individual learners (Tomlinson, 1999; Tomlinson et al., 2003). Practitioners learn to be responsive to the child: to respond positively to the child's attempts at communication, to pause frequently to allow the child to take a turn in the conversation, to base conversations around child-directed activities, and to use contingent language responsive to the child's interests, all of which allows them to use the children's own interests to teach sophisticated vocabulary and explore challenging topics (Cabell et al., 2015; Gest et al., 2006; Girolametto et al., 2003; Piasta et al., 2012; see Whorrall and Cabell, 2016, Table 1, for a summary). Finally, they are taught to avoid explicit correction when children make errors and, instead, to provide feedback in the form of recasts and expansions (e.g. Cleave et al., 2015; Nicholas et al., 2001).

Given how closely training programmes follow the published literature on techniques known to promote child language acquisition, we might expect to find robust effects of such training: both on practitioners' knowledge about how to support children's language development and on practitioner behaviour when interacting with children. However, training and knowledge provision is often not enough to trigger a long-term change in behaviour (see e.g. Marteau and Lerman, 2001; Walls et al., 2009, for evidence about the difficulty of changing behaviour via public health initiatives) and, indeed, the literature as a whole reports mixed results. For example, Pelatti et al. (2014) found that, despite a significant effort to provide effective language and literacy training in the US over the last 5-10 years, preschool practitioners were 
still not providing children with many language-learning opportunities. The four-year-olds they studied spent only an average of 3.52 minutes per day in conversations likely to facilitate language development, with large individual differences across practitioners (0-16.83 minutes). Similarly, Dickinson et al. (2013) reported that even during conversation-promoting activities, practitioners provided children with very few opportunities for practising language. Practitioners produced 80 per cent of the talk that occurred, much of which was the practitioner commenting on what the child was doing, with little response from the child (for studies showing small or null effects, see e.g. Buysse et al., 2010; Piasta et al., 2017). On the other hand, some studies have reported positive effects; Early et al. (2017) found a strong positive effect from a state-sponsored training programme (Making the Most of Classroom Interactions) on both the emotional and instructional support provided by preschool practitioners (for other studies that report positive effects on some, or all, outcome variables, see also Landry et al., 2011; Powell et al., 2010; Wasik and Hindman, 2011).

A recent meta-analysis synthesizing the literature up to 2014 (MarkussenBrown et al., 2017) reported an overall small positive effect of languagefocused professional development training on the way in which practitioners interact with, and instruct, children in the classroom (process quality), a large effect on improvements to the physical literacy environment, such as the provision of print resources (structural quality), but no effect on educator knowledge. However, the authors were rightly cautious in their conclusions because the pool of studies eligible to be included was small (25), and because there were moderate-to-large differences in the effect sizes across studies, suggesting heterogeneity in the effectiveness of different training types. In particular, their conclusions about the effectiveness of training on practitioner knowledge were tentative, since they were based on only small numbers of trials. They commented that further studies of more interventions are required before firm conclusions can be drawn. The authors also stated that, since all but one of the included trials were in the US or Canada, the results might not generalize to other countries. In other words, more empirical work, especially in non-North American countries, is needed.

The aim of the present study was to add to the literature on early languagefocused training programmes by evaluating the training provided to preschool practitioners across one Local Authority in the UK (Local Authorities are responsible for providing public services such as education in a local area). This particular Local Authority has a specially commissioned School Readiness Team, whose purpose is to ensure that children are 'school ready'; 'resilient 
and confident, with a keenness to learn and have effective personal and social skills' (http://www.seftoneducation.uk/Services/2151). They support and monitor all preschool providers within the local area, including maintained nursery and reception classes, childcare providers and Children's Centres, and do direct work with families. Part of their remit is to provide languagefocused training programmes for practitioners working with children aged 0-5 years, which they do in collaboration with the Authority's speech and language therapy team.

We focused on four aspects of training provision that are under-represented in the literature so far, and thus require further evaluation. First, we evaluated a professional development programme that was designed and developed outside the research community. As Piasta et al. (2017) have pointed out, many published studies evaluate the effect of training devised by researchers, either for the explicit purpose of the study or as a first step towards developing a professional programme. However, most practitioners undergo statesponsored training that is provided by a commercial company or charity, or devised in-house by local speech and language therapist teams, and ' $\mathrm{t}]$ here is decidedly little evidence regarding the nature, quality, and impact of such realworld PD offerings and the value-added of such investments' (Piasta et al., 2017: 356). This is particularly worrying since researcher-devised programmes are often delivered on a smaller scale and are more intensive than state-sponsored programmes; both likely to inflate effect sizes (MarkussenBrown et al., 2017). In this study, we evaluate the effect of state-sponsored (i.e. Local Authority) training provided to preschool centres.

Second, we evaluated the effect of training on practitioners' knowledge of language and cognitive development. Many training programmes are based on an implicit theory of change model, which states that improving practitioners' knowledge and beliefs will bring about positive changes in their behaviour by guiding the way in which they select and implement desirable language and literacy practices (Hamre et al., 2012). This implies that knowledge and behaviour change will be linked. However, Markussen-Brown's (2017) meta-analysis, which reported an effect of training on practitioner behaviour but not practitioner knowledge, throws doubt on this as a model of effective behaviour change. That said, there are not yet enough eligible studies to draw robust conclusions. Our second aim is to assess the impact of state-sponsored training provision on educators' knowledge of language and cognitive development and their use of language-promoting behaviour together.

Third, we evaluated the effect of training on different types of practitioners' behaviours by taking a more fine-grained approach than many previous 
studies. Most training provides very specific pieces of advice about how to interact with individual children (see online Appendix II), but most research studies only evaluate practitioner behaviour on a global, often classroombased, level. For example, Pelatti et al. (2014: 450) recorded simply whether practitioners engaged in '[o]pportunities that facilitate young children's general speaking and listening abilities', without coding exactly what techniques practitioners used to provide these opportunities. Similarly, many studies use the Classroom Assessment Scoring System (Pianta et al., 2008), an observation tool of practitioner-child interactions that codes how well practitioners implement their training at a global level. These studies cannot tell us whether practitioners are equally effective at implementing different types of advice (e.g. modelling language, using talk that elicits language from the child, tailoring their interactions to the child's developmental level or using expansions and recasts to feed back on the accuracy of children's own utterances). This is important information; for example, if practitioners are able to faithfully implement language modelling but not feedback, training could be modified, either to remove feedback training because it is ineffective or to find better ways to implement it.

That said, there are a few studies in which different types of languagefacilitating behaviours have been assessed separately. For example, Dickinson et al. (2014) transcribed samples of teacher speech and assessed the quantity (tokens), lexical diversity (number of different word types) and structural complexity (measured by Mean Length of Utterance (MLU)) of speech used by trained practitioners during Book reading, Group Content Instruction and Small Group Content Instruction contexts. However, they did not compare trained with untrained practitioners, nor did they assess how practitioners implemented the techniques they had learned with individual children. Similarly, Cabell et al. (2015) investigated a variety of practitioner behaviours including communication-facilitating strategies (e.g. 'uses comment to cue another turn') and language-modelling behaviours ('stresses and repeats words to make them salient'). However, these behaviours were coded from videos submitted by practitioners for evaluation during the training period and cannot tell us how well practitioners continued to use these behaviours after training. In the present study, we present a novel approach by assessing how practitioners implemented the language-promoting strategies they had previously been taught when interacting in the preschool with individual children.

Finally, as well as looking at the effect of training more generally, we tested the effectiveness of a strategy known as Language Champion (LC) training, at 
the request of our partners in the School Readiness team. In this model, at least one practitioner in a centre receives intensive language-focused training delivered by a speech and language therapist. The LC then acts as an expertise and training hub for their centre, supporting other practitioners, and advising practitioners worried about a child's speech and language. If successful, this strategy is likely to be cost-effective and time-efficient, since not every practitioner in the centre needs to undergo intensive language and communication training.

We present our results in two studies. In study 1 we focused on the effect of training on practitioner's knowledge of language and cognitive development. In study 2 we focused on how well practitioners implemented the languagepromoting behaviours they had been taught. In both studies, we evaluated the effectiveness of the training provided by the Local Authority and compared the effectiveness of LC training with other training programmes.

\section{Study I. The effect of language-focused training on practitioner knowledge}

In study 1 we tested whether the language-focused training designed and delivered by one Local Authority's School Readiness Team was effective in improving practitioners' knowledge of how to support children's language and cognitive development.

\section{Method}

Participants. Participants were preschool practitioners from centres within a Local Authority in northwest England, UK. All centres within the Local Authority were contacted by their School Readiness Team, and their practitioners were invited to take part. In total, 76 participants took part (all female), 59 who worked in private day nurseries, 14 who worked in preschools or nurseries attached to a school or Children's Centre, and three who worked at a Children's Centre. Eleven of the participants were under 25 years of age, 29 were between 25 and 45 years, and 25 were over 45 years of age (11 participants provided no age data). Twenty-four of the participants also took part in Study 2 below.

Stimuli. We assessed practitioner knowledge with the SPEAK II Survey of Parental Expectations and Knowledge About Language Learning. This was designed specifically to test caregivers' expectations and knowledge of 
young children's cognitive development and language learning, and the behaviours which promote development. It was designed by the researchers at the Thirty Million Word initiative (http://thirtymillionwords.org/), but adapted by the authors for use in the UK with preschool practitioners with the permission of the University of Chicago. Participants rated 24 statements about children's learning between 0 and 5 years of age on 5- or 6-point scales that ranged from strongly agree to strongly disagree (note that we administered a longer version of the checklist but analysed only the 24 items shown to have good reliability and validity; see Suskind et al., n.d.).

SPEAK II asks questions about when to expose children to language, reading and maths, how to support language and literacy development, how to ensure children are ready to learn in school, how to support bilingual children, and the impact of parent engagement and media use on child cognitive and language development. Participants were also asked questions about their age, gender and type of workplace (e.g. preschool attached to a school, private nursery etc.). Finally, we asked them to specify what type of language and communicative development training they had received in the last two years.

Details of the creation of the original SPEAK I and the adaptation to SPEAK II can be found in Suskind et al. (n.d., 2016). ${ }^{1}$ SPEAK II went through a rigorous process of creation including (i) item selection based on the literature and the authors' previous research; (2) revision of instructions, items and response scales through an iterative process involving cognitive interviews, expert consultations and field-testing; (3) evaluation of the psychometric properties (reliability and validity) in three field tests (total $\mathrm{N}=580$ ) and feedback from expert consultations; and (4) investigation of potential subdomains of the SPEAK through an exploratory factor analysis. The resulting 24-item SPEAK II has the following psychometric properties: items are reliable indicators of participant expectations and knowledge under the Rasch model; the measure has high reliability (Cronbach's alpha of 0.88) and high concurrent validity with other measures (e.g. parental education); and the measure has an overall Flesch Reading Ease score of 74.1 (ranging from 0 to 100, with higher scores represent easier reading levels; Williamson and Martin, 2010).

Procedure. Participants were invited by the School Readiness Team to complete the survey online (via a weblink to Qualtrics) or on paper. The paper version was completed in centres and then posted or handed back to the researcher. All participants gave written consent, online or on paper, to take part. The surveys were completed between November 2015 and April 2016. 
Coding. Responses were coded according to the coding scheme provided by the original authors. The 5-point Likert items score from 0 (most incorrect) to 4 (most correct), and the 6-point ordinal items score from 0 (most incorrect) to 5 (most correct). The maximum possible score is 104 and the minimum 0.

\section{Results and discussion}

Forty-four practitioners had attended at least one language and communication training programme, and 32 had received no training at all. Thirty-six of the trained practitioners provided information about the date of their last training course. They had undergone training, on average, seven months before taking part in the study (mean $=7.28, \mathrm{SD}=7.51$, range $=0$ to 36 months). Forty-four of the practitioners told us how many training programmes they had attended; on average, they had attended 1.82 training programmes $(\mathrm{SD}=0.84$, range $=1-3)$. The most frequently used training programmes were provided by WellComm (https://www.gl-assessment.co. uk/products/wellcomm/, completed by 22 practitioners), ICAN (Early Language Development Program http://www.ican.org.uk/ELDP, completed by 15 practitioners) and ELKLAN (http://www.elklan.co.uk/, completed by 17 practitioners). These are all 'paid-for' resources provided by private companies, with training delivered either in-house or online by the company, or in-house by Local Authority-employed speech and language therapists. Sixteen of the practitioners who received training had received LC training, 28 had received other language-focused training. The LCs had completed a two-day intensive programme created especially for the Local Authority by a Speech and Language Therapist. More details of what was involved in this, and the other most frequently accessed training programmes, can be found in online Appendix III. All programmes were language and communication-specific, and all had similar stated goals of providing practitioners with the confidence and skills to support the communication and language development of children.

Table 1 shows the mean SPEAK II scores. The mean score overall (maximum $=104)$ was $81.22(\mathrm{SD}=9.35$, range $=45-98)$. Cronbach's alpha indicated that the scale had good internal consistency $(\alpha=.802)$. Trained practitioners scored higher than untrained practitioners (see Table 1, $M=84.05$ versus 77.34), and LCs scored higher than those who had received other types of training $(\mathrm{M}=86.88$ versus 82.43$)$.

Tests of normality indicated that the data were suitable for parametric analysis after the removal of two outliers (P29 and P71), despite unequal 
Table I. Mean SPEAK survey score (SD) by training condition.

\begin{tabular}{llll}
\hline Condition & Mean (SD) & Range & $\mathrm{N}$ \\
\hline No training & $77.34(9.46)$ & $45-90$ & 32 \\
Training & $84.05(8.28)$ & $61-98$ & 44 \\
$\quad$ LC training & $86.88(8.41)$ & $61-98$ & 16 \\
$\quad$ Other training & $82.43(7.90)$ & $66-96$ & 28 \\
Mean score & $81.22(9.35)$ & $45-98$ & 76 \\
\hline
\end{tabular}

LC: Language Champion; SPEAK: Survey of Parental Expectations and Knowledge about Language Learning.

sample sizes. Thus, we ran a one-way between-subjects ANOVA with Training Condition (Training/No training) as the Independent Variable and SPEAK II score as the Dependent Variable. As predicted, trained practitioners scored significantly higher than non-trained practitioners: $F_{(1,72)}=12.15$, $\mathrm{p}=.001, \eta \mathrm{p}^{2}=.14$.

We then investigated the effect of training type (LC versus Other Training). The LCs knew significantly more than the Other training group: $\mathrm{F}_{(1,41)}=7.51, \mathrm{p}=.009, \eta \mathrm{p}^{2}=.16$. In sum, as predicted, the trained practitioners knew more than untrained practitioners about child cognitive and language development, and the LCs knew more than those who had undergone other training.

However, there was also an interaction between practitioner age and training type (see Table 2). Most of the under 25-year-olds had received no training and, contrariwise, nearly all of the over 45 -year-olds had received some training. Extremely uneven sample sizes and missing age data for 11 participants meant that it was not possible to test the interaction between Age and Training type on SPEAK II scores using inferential statistics, but it is relevant to note that, though trained practitioners scored higher on SPEAK II than untrained practitioners, the effects are numerically larger for the younger ages.

Finally, many of our practitioners had attended more than one training programme, so we tested whether this was more effective by correlating the number of programmes undertaken with SPEAK II scores. We used a non-parametric Spearman's rho test, since the data for number of training programmes attended were ordinal (1-3). There was a medium-sized significant positive correlation, indicating that the more training courses attended, the higher the SPEAK II score ( $\mathrm{rho}=.46, \mathrm{~N}=44, \mathrm{p}=.002$ ). 
Table 2. Relationship between age, training condition and SPEAK score.

\begin{tabular}{lllr}
\hline Training & Age & Mean SPEAK score (SD) & $\mathrm{N}$ \\
\hline Untrained & Under 25 years & $75.89(8.45)$ & 9 \\
& $25-45$ years & $78.33(7.1 \mathrm{I})$ & 12 \\
& 45 years + & $83.00(6.56)$ & 3 \\
Trained & Under 25 years & $78.50(24.75)$ & 2 \\
& LC Training & $61.00(-)$ & 1 \\
& Other training & $96.00(-)$ & 1 \\
& 25-45 years & $82.82(9.27)$ & 17 \\
& LC Training & $92.50(4.93)$ & 13 \\
& Other training & $79.85(8.22)$ & 22 \\
& 45 years + & $85.68(5.74)$ & 10 \\
LC Training & $87.11(4.58)$ & 12 \\
Other training & $84.50(6.51)$ &
\end{tabular}

LC: Language Champion; SPEAK: Survey of Parental Expectations and Knowledge about Language Learning.

\section{Study 2. Implementing language-promoting techniques in interactions}

In Study 2 we tested whether practitioners could effectively implement the language boosting techniques they had been taught when interacting with 2- and 3-4-year-old children in preschool centres. We also tested whether practitioners in LC centres would use more language-promoting behaviours than practitioners in other centres.

Our goal here was to evaluate the effect of training on practitioners' behaviour in a more fine-grained way than has previously been the norm, so that we could assess directly how practitioners implement the different techniques they are taught. To this end, we video-recorded practitioners playing one to one with either a 2- or a 3-4-year-old child with whom they were familiar. We focused on the four techniques commonly taught to UK preschool practitioners as part of training; whether trained practitioners (1) were more effective at modelling enriched language (e.g. using more open questions and fewer behavioural directives); (2) responded more appropriately to the children's own attempts at communication; (3) gave children more chances to engage in, and to direct, the interaction; and (4) were more likely to adjust the length and complexity of their utterances to the age and language level of the child. 


\section{Method}

Participants. Preschool centres within the Local Authority were invited to participate by the School Readiness team. Centres who expressed an interest were then contacted by the first author. Six centres agreed to take part, three of which had an LC embedded within the staff, and three which did not. All centres were in the same Local Authority area; five were private day nurseries and one was a preschool attached to a school. Five of the six had received a Good rating at their last official (OFSTED) inspection (one centre had not yet had its first inspection at the time of the study). The sizes of the centres ranged from 25 to 219 children on the roll (average 89 children), with the LC centres tending to take more children (57, 93, 219 children, respectively) than the others (25, 63, 79 children). The University Ethics Committee approved the study and all parents and staff gave informed consent prior to taking part.

Each centre identified four practitioners to take part and two 2-year-old and two 3-4-year-old children who knew these practitioners well. Bilingual children, and those with severe additional needs or speech impairments, were excluded. In total 24 practitioners (all women), 12 two-year-old children (mean age $=2.7$, range $=2.3-2.11$; seven girls) and 12 three to four-year-old children (mean age $=4.2$, range $=3.2-4.11 ; 10$ girls) took part, resulting in 24 adult-child dyads, 12 from LC nurseries.

Details of age, academic and professional qualifications, and language and communication training undertaken by the practitioners can be found in online Appendix IV. All 24 practitioners were native English speakers. Seven were under 25 years of age (LC centres $N=5$; non-Language Champion (NLC) centres $\mathrm{N}=2$ ), 15 were between 25 and 45 years of age (LC centres $\mathrm{N}=6$; NLC centres $\mathrm{N}=9$ ) and two were over 45 years of age (LC centres $\mathrm{N}=1$; NLC centres $\mathrm{N}=1$ ). Levels of academic and professional qualifications were similar across the two types of centres. Of those practitioners for whom we had qualification data, most were school or college leavers with either GCSEs (General Certificate of Education academic qualifications usually taken at age 16 years; $N=5$ for both LC and NLC centres) or A-levels (advanced level, post-GCSE, academic qualifications usually taken between age 16 and 18 years; LC Centres: $N=2$; NLC centres: $N=1$ ). Only two practitioners had graduate qualifications (university degrees), one in an LC, and one in an NLC centre.

In terms of professional qualifications, most practitioners had NVQ level 3 (a vocational qualification equivalent to academic A-levels: LC centre: $\mathrm{N}=8$, NLC centre: $\mathrm{N}=6$ ), and one, in an LC centre, had NVQ level 2 (equivalent to 
academic GCSEs). Again, only two practitioners had graduate practitioner qualifications, one in an LC, and one in an NLC centre. Eight of the practitioners in LC centres had completed Language and Communication Training programmes (11 programmes in total), compared to only two of the practitioners in NLC centres (four programmes in total). All practitioners were native British English speakers.

Stimuli and procedure. All staff completed the SPEAK II survey (see study 1 above). Parents of the two-year-old children filled in the Lincoln Communicative Development Inventory (Lincoln CDI), a parental report instrument of vocabulary for children up to 30 months. Like the MacArthur Bates CDI Words and Sentences devised for American children aged 16-30 months, the Lincoln CDI contains a word list of common vocabulary items $(\mathrm{N}=668)$ that parents tick to indicate what words their children can say (Fenson et al., 2006). However, unlike the MacArthur-Bates CDI, the Lincoln CDI is not yet standardized for the population. Because parents tend to be less accurate at recalling receptive vocabulary (Houston-Price et al., 2007), we calculated expressive vocabulary scores only (using the Understands \& Says scale of the CDI). The three-year-olds completed two subscales of the CELF-Preschool 2-UK (Clinical Evaluation of Language Fundamentals, Wiig et al., 2006), one which measures receptive language (Basic Concepts) and one expressive language (Recalling Sentence in Context). For parity with the two-year-old measure, we only used the Expressive Language scores.

Each practitioner-child dyad was video-recorded for 15 minutes playing one to one in a separate room or a corner of the main room, away from other children in the centre, with a set of toys brought in by the researcher (a traintrack set for small world, books and jigsaws for numeracy and literacy, musical instruments and puppets for imaginary play). The practitioners were simply told to play normally with the child, as they would play on a typical day. The videos were transcribed and coded in ELAN (https://tla.mpi.nl/tools/tlatools/elan/).

Coding. To code the videos for language-promoting behaviours, we operationalized the messages given in nine training resources, seven of which are used widely across the UK, and two of which were specifically created by our partner Local Authority's Speech and Language Therapy team to train their practitioners (see online Appendices I and II). First, we coded the practitioners' own use of language to test how well they implemented the advice 
about providing enriched language (Enrich). Every practitioner utterance was coded into one of eight utterance types, four which implement languagepromoting behaviours (Comment, Open Question, Prompt, Routines) and four which do not (Behavioural-directive, Attention-directive, Yes-no question, Other). We calculated an overall Enrich score in which the number of language-promoting utterances was divided by the total number of utterances produced by the practitioner in the 15-minute session. We also analysed whether practitioners used co-speech gestures as recommended in many of the training resources (e.g. "use non-verbal communication (e.g. gesture) to help the child to understand...'). For this, we calculated the proportion of practitioner utterances that were accompanied by a gesture (Gesture).

Second, we coded practitioner responses to the child's own attempts at communication (Respond). Every time the child spoke or made a communicative gesture (e.g. pointing or holding up a toy), we coded the practitioner's response into one of the following categories; Ignore, Copy, Rephrase, Expand, Interpret, Change topic, Non-verbal response, Other response. We then created two Respond variables. First, since some of the advice in the training manuals is quite broad, suggesting that what matters is simply to respond (i.e. not ignore) the child's attempts to communicate, we created a broad AnyResponse score. For this we calculated the proportion of child utterances that elicited a response from the practitioner (i.e. all responses minus Ignore responses). However, from our reading of the literature, we suspect that responses that simply praise, copy or encourage the child are likely to be less effective than those that model new language, at least for 2- and 3-4-year-old children. So we suggest that the most effective responses might be Expand (adult repeats what the child has said and adds new information) and Interpret (adult interprets the child utterance and continues on the same topic as the child). Thus, we also calculated a more narrowly defined Expand \& Interpret Response score: the proportion of child utterances that elicited an Expand or Interpret response from the practitioner. Finally, within the Respond category, we also coded the practitioners' responses to children's errors to assess the number of recasts that the practitioners used. However, the children produced too few errors for analysis $(0.88$ errors on average), so we do not consider these results further.

Third, we analysed whether the trained practitioners gave children more chances to engage in, and direct, the interaction. For the first of these measures, we focused on turn-taking. The training resources advise that practitioners 'avoid adult-dominated interactions' and 'allow children to take turns'. Thus, we calculated the proportion of child turns in the conversation as a 
function of the total number of turns (Proportion of Child Turns). For the second of these measures, we focused on whether the child was allowed to lead the choice of activity. We calculated the proportion of activity changes during the 15-minute session that were child-led (Proportion of Child-led Activities).

Fourth, and finally, we looked at how the practitioners adjusted their speech to the children's developmental level: both to the child's age (2-year-olds/ 3-4-year-olds) and to their language ability. We transcribed 5 minutes of practitioner speech from the middle of the session and used the CLAN programs from the CHILDES website (MacWhinney, 2000) to calculate, for each practitioner, an MLU score in morphemes. MLU is a measure of how long and complex a participant's utterances are (see Brown, 1973). The higher the MLU, the longer and more complex the utterance.

All coding was done by the first author. The second author independently second-coded four videos (17\%), yielding good levels of reliability: \% agreement $=83.06 \%$, Kappa $=0.79(\mathrm{SE}=0.02)$.

\section{Results and discussion}

Practitioner Language and Communication training. Details of the numbers and names of the Language and Communication training programmes attended by the practitioners are in online Appendix IV. On average, the trained practitioners had attended 1.5 training programmes in the last two years $(S D=0.53$, range $=1-2$ ), with an average of 7.33 months between completion of the last programme and the start of the study $(\mathrm{SD}=6.20)$. Of the practitioners at the LC centres, two had received LC training, six had received other types of training, and four had received no training. The level of training at the NLC centres was much lower; none had received LC training and only two had received other training, leaving 10 who had received no training. Because none of the practitioners in the NLC centres had received LC training, our Training variable in the analyses below distinguished simply between Trained and Untrained practitioners.

Proportion of practitioner utterances that were language-boosting. Our first set of analyses tested whether trained practitioners, and practitioners from LC centres, were more likely to use language-enriched utterance types (our composite Enrich score), were more like to use co-speech gestures (our Gesture score) and were more likely to respond to child attempts at communication (our broad composite AnyResponse and our narrow composite Expand\&Interpret Response 
Table 3. Mean proportion of practitioner utterances that were language-promoting: Gesture, Enrich and Response scores by Centre and Training (SD).

\begin{tabular}{|c|c|c|c|c|c|}
\hline \multirow[b]{2}{*}{ Centre type } & \multirow[b]{2}{*}{ Training (N) } & \multicolumn{4}{|c|}{ Proportion of practitioner utterances } \\
\hline & & Gesture & Enrich & AnyResponse & $\begin{array}{l}\text { Expand \& } \\
\text { Interpret } \\
\text { Response }\end{array}$ \\
\hline \multirow{3}{*}{$\begin{array}{l}\text { Non-Language } \\
\text { Champion (NLC) }\end{array}$} & No training $(10)$ & $0.32(0.10)$ & $0.51(0.08)$ & $0.96(0.06)$ & $0.46(0.12)$ \\
\hline & Training (2) & $0.37(0.09)$ & $0.55(0.06)$ & $1.00(0.00)$ & $0.63(0.11)$ \\
\hline & Total (12) & $0.33(0.10)$ & $0.51(0.08)$ & $0.96(0.06)$ & $0.49(0.13)$ \\
\hline \multirow{3}{*}{$\begin{array}{l}\text { Language } \\
\text { Champion (LC) }\end{array}$} & No training (4) & $0.39(0.18)$ & $0.52(0.09)$ & $0.98(0.03)$ & $0.71(0.10)$ \\
\hline & Training (8) & $0.35(0.16)$ & $0.60(0.06)$ & $0.99(0.01)$ & $0.66(0.06)$ \\
\hline & Total (12) & $0.36(0.16)$ & $0.57(0.07)$ & $0.99(0.02)$ & $0.67(0.07)$ \\
\hline \multirow[t]{3}{*}{ All centres } & No training (14) & $0.34(0.13)$ & $0.51(0.08)$ & $0.96(0.05)$ & $0.53(0.16)$ \\
\hline & Training (10) & $0.35(0.14)$ & $0.59(0.05)$ & $0.99(0.01)$ & $0.65(0.07)$ \\
\hline & Total (24) & $0.34(0.13)$ & $0.54(0.08)$ & $0.98(0.04)$ & $0.58(0.14)$ \\
\hline
\end{tabular}

score). On average, the practitioners produced 177 utterances in total $(\mathrm{SD}=27.55)$. Table 3 presents how often (mean proportion of utterances) our practitioners used the different language-promoting behaviours. The Enrich and Response scores are composite measures, so online Appendices $\mathrm{V}$ and VI provides these scores broken down by individual behaviours. Tests of normality revealed that all of our variables were suitable for parametric testing, except for the broad AnyResponse category. Non-parametric tests were used to test the hypotheses involving this variable.

Uneven sample sizes (in particular, only two practitioners in the NLC $\times$ training cell) meant that we had to analyse the effect of Training and Centre type separately. Our first analysis tested the effect of Centre type in a two-way mixed effects ANCOVA. Independent variables were Centre type (LC/NLC) and Behaviour type (Enrich/Gesture/Expand\&Interpret Response). Centre identity was included as a covariate, since there were four practitioners from each of six centres. The Dependent Variable was the proportion of relevant practitioner behaviours that were language-promoting. Preliminary analyses revealed no interactions with child age or practitioner age (all ps $>.05$ ), so these were not included in the final model (note that because only one practitioner at the NLC nurseries was over 45 years, we combined the 25-45 and 45+ age categories for all analyses including practitioner age). 
There was an overall main effect of Behaviour; $\mathrm{F}_{(2,42)}=14.25, \mathrm{p}<.001$, $\eta_{p}^{2}=.40$, which reflects the fact that, on average, $54 \%(\mathrm{SE}=2 \%)$ of practitioner utterances, and $58 \%(\mathrm{SE}=2 \%)$ of practitioner responses to child utterances, were language-promoting, but only 34\% ( $\mathrm{SE}=3 \%$ ) of practitioner utterances were accompanied by co-speech gestures. However, this is not necessarily a surprise as there are a limited number of utterance types that are appropriate for co-speech gestures. There was also a main effect of Centre type, $\mathrm{F}_{(1,21)}=6.27, \mathrm{p}=.02, \eta_{\mathrm{p}}^{2}=0.23$, with a greater proportion of language-promoting behaviours overall in the $\mathrm{LC}$ centres $(\mathrm{M}=0.53, \mathrm{SE}=0.02)$ than in the NLC centres $(M=0.44, S E=0.02)$. There was no interaction between Behaviour and Centre type $\left(\mathrm{F}_{(2,42)}=1.47, \mathrm{p}=.24, \eta_{\mathrm{p}}^{2}=0.07\right)$. That said, independent t-tests run on the three behaviours separately showed that practitioners in LC centres produced significantly more Enrich $(t=1.91, \mathrm{df}=22, \mathrm{p}=.04)$ and Expand \& Interpret Response utterances $(t=4.37, d f=22, p<.001)$ but not more co-speech gestures $(t=0.59$, $\mathrm{df}=22, \mathrm{p}=.28$, all tests one-tailed) than those in NLC Centres.

We next ran a two-way mixed effects ANCOVA to test the effect of Training (Training/No Training) and Behaviour type (Enrich/Gesture/Expand \& Interpret Response) on language-promoting behaviours, once again including Centre identity as a covariate. Preliminary analyses revealed no interactions with child age or practitioner age (all ps $>.05$ ), so these were not included in the final model. As above, there was a main effect of Behaviour $\left(F_{(2,42)}=20.55, p<.001, \eta_{p}^{2}=.50\right)$. However, there was no main effect of training $\left(\mathrm{F}_{(1,21)}=3.34, \mathrm{p}=.08, \eta_{\mathrm{p}}^{2}=0.14\right)$ and no interaction between Training and Behaviour $\left(\mathrm{F}_{(2,42)}=1.07, \mathrm{p}=.35, \eta_{\mathrm{p}}^{2}=0.05\right)$. That said, independent t-tests run on the three behaviours separately showed that the effect of training reached significance for Enrich and Expand \& Interpret behaviours; Enrich: $t=2.75, d f=22, p=.006$; Expand \& Interpret ${ }^{2}: t=2.63, d f=22$, $\mathrm{p}=.009$, though not Gesture $(\mathrm{t}=-0.21, \mathrm{df}=22, \mathrm{p}=0.42$, all tests onetailed).

We also tested the effect of Centre type and Training on our broad response category (AnyResponse). Because the data were not normally distributed, we ran two Mann-Whitney tests, one for Centre type and one for Training type. There was no effect of Centre type $(\mathrm{z}=-0.34, \mathrm{~N}=24, \mathrm{p}=.74)$ or Training type $(\mathrm{z}=-1.73, \mathrm{~N}=24, \mathrm{p}=.08)$. All practitioners responded to the vast majority of children's utterances (mean $=0.98, \mathrm{SD}=0.04$, range $=0.84-1.00$ ).

Opportunity for child engagement: Our second set of analyses focused on whether the trained practitioners gave children more chances to engage in the activity (Proportion of Child Turns), and whether the child was allowed to 
Table 4. Mean proportion of child turns and child-led activity by Centre and Training type (SD).

\begin{tabular}{llll}
\hline Centre type & Training type $(\mathrm{N})$ & Child turns & Child-led activity \\
\hline Non-Language Champion & No training $(10)$ & $0.37(0.10)$ & $0.82(0.21)$ \\
& Training $(2)$ & $0.34(0.12)$ & $1.00(0.00)$ \\
& Total $(12)$ & $0.36(0.10)$ & $0.85(0.21)$ \\
Language Champion & No training $(4)$ & $0.41(0.05)$ & $0.93(0.15)$ \\
& Training (8) & $0.38(0.08)$ & $0.79(0.20)$ \\
All centres & Total (I2) & $0.39(0.07)$ & $0.84(0.19)$ \\
& No training (14) & $0.38(0.09)$ & $0.85(0.20)$ \\
& Training (I0) & $0.37(0.08)$ & $0.83(0.19)$ \\
& Total $(24)$ & $0.37(0.08)$ & $0.84(0.19)$ \\
\hline
\end{tabular}

lead the choice of activity (Proportion of Child-led Activities). Table 4 shows the proportion of child turns in the conversation as a function of the total number of turns (Proportion of Child Turns), and the proportion of activity changes that were child-led (Proportion of Child-led Activities) by Centre and Training.

Tests of normality revealed that our variables were not suitable for parametric testing so we ran separate Mann-Whiney tests for Centre type and Training. In preliminary analyses, we checked for effects of child and practitioner age, but there were no effects of either of these so they were not included in the final model. For Child Turns, there were no effects of either Centre status (LC versus NLC) or training on the proportion of child turns; Centre: $\mathrm{z}=-0.41, \mathrm{~N}=24, \mathrm{p}=.71$; Training: $\mathrm{z}=-0.09, \mathrm{~N}=24, \mathrm{p}=.93$. In sum, the adults tended to dominate the conversation in terms of the number of turns (children took only $37 \%$ of the turns $(\mathrm{SD}=8 \%$ )) but there were no differences between Centres or Training categories in either case. For the child-led activity there was also no effect of either Centre or Training; Centre: $\mathrm{z}=-0.15, \mathrm{~N}=24, \mathrm{p}=.88$; Training: $\mathrm{z}=-0.16, \mathrm{~N}=24, \mathrm{p}=.88$. Overall, the children chose the activity on average $84 \%$ of the time (SD $=19 \%)$, meaning that nearly all activity changes were child-led.

Adjustment to child's developmental level: Third, and finally, we looked at how the practitioners adjusted the length and complexity of their speech to the children's developmental level (2-year-olds/3-4-year-olds). We transcribed 5 minutes of practitioner speech from the middle of the session and used the CLAN programs to calculate MLU. Table 5 shows the mean MLU by Centre, Training type and Age. Uneven distribution of practitioners 
Table 5. Mean practitioner MLU by Centre, Training, and Child age (SD).

\begin{tabular}{|c|c|c|c|}
\hline Centre type & Training type & Child age (N) & Practitioner MLU \\
\hline \multirow[t]{9}{*}{ Non-Language Champion } & \multirow[t]{3}{*}{ No training } & 2 -year-olds (6) & $3.90(0.74)$ \\
\hline & & 3-4-year-olds (4) & $4.12(1.28)$ \\
\hline & & Total $(10)$ & $3.95(0.93)$ \\
\hline & \multirow[t]{3}{*}{ Training } & 2 -year-olds (0) & - \\
\hline & & 3-4-year-olds (2) & 3.75 (I.29) \\
\hline & & Total $(10)$ & $3.75(1.29)$ \\
\hline & \multirow[t]{3}{*}{ Total } & 2-year-olds (6) & $3.90(0.74)$ \\
\hline & & 3-4-year-olds (6) & $3.99(1.17)$ \\
\hline & & Total (I2) & $3.95(0.93)$ \\
\hline \multirow[t]{9}{*}{ Language Champion } & \multirow[t]{3}{*}{ No training } & 2-year-olds (I) & $5.03(-)$ \\
\hline & & 3-4-year-olds (3) & $5.00(1.19)$ \\
\hline & & Total $(4)$ & $5.01(0.97)$ \\
\hline & \multirow[t]{3}{*}{ Training } & 2 -year-olds (5) & $4.48(0.58)$ \\
\hline & & 3-4-year-olds (3) & $4.48(0.77)$ \\
\hline & & Total (8) & $4.48(0.60)$ \\
\hline & \multirow[t]{3}{*}{ Total } & 2 -year-olds (6) & $4.57(0.56)$ \\
\hline & & 3-4-year-olds (6) & $4.74(0.94)$ \\
\hline & & Total (12) & $4.66(0.75)$ \\
\hline \multirow[t]{9}{*}{ All centres } & \multirow[t]{3}{*}{ No training } & 2-year-olds (7) & $4.06(0.80)$ \\
\hline & & 3-4-year-olds (7) & $4.50(1.23)$ \\
\hline & & Total (14) & $4.28(1.02)$ \\
\hline & \multirow[t]{3}{*}{ Training } & 2 -year-olds (5) & $4.48(0.58)$ \\
\hline & & 3-4-year-olds (5) & $4.18(0.94)$ \\
\hline & & Total $(10)$ & $4.33(0.75)$ \\
\hline & \multirow[t]{3}{*}{ Total } & 2-year-olds (I2) & $4.23(0.72)$ \\
\hline & & 3-4-year-olds (I2) & $4.37(1.08)$ \\
\hline & & Total (12) & $4.30(0.90)$ \\
\hline
\end{tabular}

across training status meant that we could not analyse the effect of Training and Centre type together so we conducted separate one-way ANCOVAs for Centre type and Training. In both cases, we included Centre identity as a covariate, and the Dependent Variable was Practitioner MLU. Preliminary analyses showed that practitioner age did not interact with our predictors, so it was not included in the final model. For Centre, there was a main effect of Centre type; the LC practitioner utterances were significantly longer than those in the NLCs (LC: $M=4.77, \quad S D=0.75, \quad N L C: M=3.95, \quad S D=0.93$; $\left.\mathrm{F}_{(1,19)}=5.26, \quad \mathrm{p}=.03, \eta_{\mathrm{p}}^{2}=.22\right)$, but with no effect of Age and no 
interaction between Age and Centre type (both ps > .10). For Training, there were no significant main effects and no interactions (all ps $>.10$ ). In other words, there were no adjustments for the age of the child in any of the groups.

The practitioners did, however, adjust to the language level of the two-year olds, which differed substantially both individually and across centres (LC centres: CDI Understands\&Says mean score $=600.33, \mathrm{SD}=82,84$; NLC centres: mean $=321.40, \mathrm{SD}=289.75$; note that we have missing data for one NLC child). Regardless of training or centre type, the best predictor of practitioner MLU when interacting with two-year olds was the size of the children's expressive vocabulary, as measured by the Lincoln CDI (Pearson's $r=.69$, $\mathrm{N}=11, \mathrm{p}=.02$ ). This, however, did not hold for the practitioners interacting with the 3-4-year-olds. Although the 3-4-year olds also showed large individual differences in their language level $(\mathrm{LC}$ Mean $=20.00, \mathrm{SD}=22.31$, Range $=51$; NLC Mean $=24.30, \mathrm{SD}=20.63$, Range $=47)$, there was no association between practitioner MLU and language level $(r=-.09$, $\mathrm{N}=12, \mathrm{p}=.78$ ). In other words, all practitioners adjusted the length and complexity of their own speech to the developmental language level of the two-year-olds, but not to the 3-4-year-olds.

\section{General discussion}

The goal of this research was to investigate the effect of language and communication focused training on the knowledge and behaviour of preschool practitioners in the UK. In Study 1, we used the SPEAK II questionnaire to assess whether the training received by practitioners was effective in improving caregivers' knowledge of young children's cognitive and language development. All practitioners performed well on the survey. However, those who had received training scored significantly higher than those who had received no training, and those who received LC training had the highest scores. Thus, Study 1 provided good support for the claim that language-focused training, especially LC training, provides practitioners with accurate and memorable information about how children learn and about how to support their language development.

In Study 2, we tested whether practitioners could effectively implement the language-promoting techniques they had been taught when interacting with 2- and 3-4-year-old children in preschool centres. Our first set of analyses tested whether trained practitioners, and practitioners from LC nurseries, were more likely to use language-enriched utterance types, were more likely to use co-speech gestures, and were more likely to respond to child utterances 
effectively. We found good support for the effectiveness of the LC model. As predicted, the practitioners in the LC centres produced a greater proportion of language-enriched utterances (Enrich) than those in the centres without an LC. The Enrich category contained utterance types that have been shown to promote children's language development: descriptive comments, open questions, prompts and routines (book reading, nursery rhymes, songs). However, although significantly different, the differences between the LC and NLC centres were not numerically large (Enrich: mean $=57 \%$ versus $51 \%$ ), and these utterances comprised only just over half of all practitioner utterances. Online Appendix V shows the data for each of the behaviours individually. The majority of the practitioners' language-promoting utterances were comments and open questions (together, $51 \%$ in LC and $45 \%$ in NLC), with only $2 \%$ and $3 \%$ of utterances constituting routines and prompts. Thus, even in LC centres, there is scope for increasing the numbers of routines and prompts used by practitioners.

In terms of responding (Respond categories), practitioners in both types of centre overwhelmingly responded to children's utterances and non-verbal attempts at communication (99\% in LC versus $96 \%$ in NLC centres). Thus, practitioners were very rarely ignoring children's attempts at communication. However, the LC practitioners produced a significantly greater number of language-promoting Expand ('adult repeats what the child has said and adds new information') and Interpret ('adult interprets what the child has said and continues on the same topic') responses to children's own utterances. Here the differences were numerically substantial too (67\% of responses in LC centres compared to only $49 \%$ in NLC centres). Online Appendix VI presents the data for each of these behaviours individually, showing that Interpret responses comprised the largest category of responses, and LC practitioners were using substantially more Interpret responses than those in NLC centres (50\% versus $36 \%$ ), but also more Expand responses (17\% versus $12 \%)$. These are extremely effective strategies for language learning, since they model new language that is directly related to what the child has just shown an interest in communicating. The LC practitioners also produced a greater proportion of co-speech gestures (36\% versus 33\%), but these differences did not reach significance when analysed separately from the other behaviours in an independent t-test.

The results for the effect of Training on Enrich, Respond and Gesture categories show a similar trend, though the pattern is less clear-cut. There was no effect of Training in our omnibus ANCOVA analysis, but there were significant differences for both Enrich (59\% versus 51\%) and Expand \& 
Interpret responses (65\% versus 53\%) in independent t-tests run for each behaviour individually. In addition, there were substantial differences in how trained and non-trained practitioners responded to children in NLC centres (Interpret\&Expand: 63\% versus 46\%). Thus, we suggest that further work looking at whether training is effective in centres where there is no overall focus on language and communication (i.e. no LC present) may be fruitful.

In our second and third sets of analyses, we found no effects of either Centre or Training. Our second set of analyses tested whether the trained practitioners gave children more chances to engage in, and direct, the interaction focusing on turn-taking (Child Turns) and whether the child was allowed to lead the choice of activity (child-led activity). Our third set of analyses assessed how practitioners adjusted their speech to the children's age (two-year-olds/three-year-olds). None of these analyses yielded significant results.

In general, the absence of the predicted difference for our child-led activity variable is unsurprising, given that there is a near-ceiling effect in the data; all the adults allowed the children to choose the activity most of the time, though this was more common with three-year-olds (89\% of activity choices were child-led) than with two-year-olds (79\%). However, with turn-taking, both two- and three-year-olds contributed fewer than half of the turns (37 and $38 \%$, respectively). Thus, although most of the training resources we analysed encouraged adults to avoid adult-dominated interactions and to balance adultchild turns, this advice did not translate well in practice. It may be necessary to find alternative strategies to encourage practitioners to avoid adultdominated conversations. For example, open questions, pauses and prompts are effective techniques to encourage children to take part in conversations and could be utilized more by all practitioners.

The implications of null results in our third set of analyses are less clear. Contrary to our predictions, the utterances that practitioners addressed to two-year-olds (MLU $=4.23$ ) were not significantly shorter and simpler than those addressed to $3-4$-year-olds $(\mathrm{MLU}=4.37)$ in any of our practitioner groups. There are a number of possible reasons for this. One is that practitioners are failing to adapt to the different language levels of 2- and 3-4-yearold children. However, this does not seem likely given that the best predictor of the MLU of the practitioners interacting with the two-year-olds was the size of the children's expressive vocabulary. In other words, practitioners, whether trained or not, were very effectively adapting their speech to each two-yearold child's individual developmental level. Another possibility is that all 
practitioners are very good at adapting to children's development level, making training unnecessary. However, this too is unlikely since there was no significant adaptation to the 3-4-year-olds' expressive language level; practitioner MLU did not correlate with the CELF expressive language scores for these children.

A third possibility is that practitioners are very good at adapting their speech to that of younger children, but less good with older children, and that the training they receive fails to compensate for this. This possibility deserves further scrutiny. Although all the training resources recommend that practitioners adapt their language to the individual child, the specific advice given about how to do this tends to focus on shortening and simplifying speech (e.g. 'Keep your language simple, Use short simple sentences'). This may not be the best advice for interacting with three- and four-year-olds, who benefit more from a more sophisticated use of language, and from hearing rare words, explanations and discussions about pretence and makebelieve (Rowe, 2012). Therefore, it may be useful to revisit the advice given in training resources to ensure that it reflects the needs of advanced, and older, preschoolers, as well as the needs of younger children.

Finally, we found stronger effects of training on practitioner knowledge about language and communicative development (study 1) than on their use of the language-facilitating behaviours they had been taught (study 2). Thus, taken as a whole, our results suggest that an implicit theory of change model, which proposes that improving practitioners' knowledge and beliefs will bring about positive changes in their behaviour (Hamre et al., 2012), does not fully apply in this training context. This finding is consistent with research on the effectiveness of mass-media public-health campaigns (e.g. to reduce obesity or smoking), which has repeatedly shown that campaigns to improve knowledge about the risks and benefits of certain behaviours usually fail to yield strong, lasting effects on how often people engage in these behaviours (for one of the earliest explorations of the weak, albeit positive, correlation between knowledge and behaviour, see Bettinghaus, 1986).

Some of the factors from this literature that are known to inhibit behaviour change do not apply in the current context; factors such as the addictive nature of the behaviour (e.g. smoking or alcohol consumption) and social pressures to conform to a group. However, other factors are relevant, in particular, the idea that it is difficult to sustain behaviour change long-term. Many practitioners are likely to have entrenched ways of interacting with children, which may be hard to change, especially if the required change are quite effortful. For example, adjusting your language to the child's 
developmental level can be particularly challenging since it requires continuous monitoring of the child's communicative efforts and a sophisticated understanding of the child's linguistic strengths and weaknesses. It is, thus, perhaps not surprising that the practitioners found this advice difficult to implement. In response, we note that some training programmes include a continuous evaluation stream in which practitioners video-record themselves interacting with children, and then assess their own performance together with the trainer (see e.g. Cabell et al., 2011). We do not know whether this strategy would be successful at changing the behaviours that seem most resistant to change in the present study, but this would be a fruitful avenue to explore in future.

\section{Limitations and conclusions}

There were a number of limitations of the present work. First, in Study 2, we did not observe practitioner behaviour in the classroom, only how practitioners interact with individual children one to one. This was a deliberate decision, to allow us to code their behaviours in a fine-grained way, rather than on a global, classroom-based scale. However, since it is more difficult to implement language-promoting behaviours in a busy classroom, it is likely that we have overestimated the frequency with which practitioners use these behaviours. Second, in future studies, we should also consider the role of the child in interactions. A child's developmental level, and temperament, is likely to have a large effect on how well practitioners are able to implement trained behaviours. For example, it is harder to use a responsive, child-led mode of interaction with quieter children, or with children with lower levels of language, which means that practitioners may find it harder to use languagefacilitating behaviours with precisely those children who need it most. Third, it is possible that our measures of the child's language level were not accurate enough or were not capturing the type of variation that practitioners are adapting too (e.g. child MLU). Future studies should include multiple measures of child language in order to assess this possibility. Fourth and finally, uneven sample sizes for some analyses in Study 1 and small sample sizes in Study 2, due to the labour-intensive nature of the coding, mean that replications are required to confirm the robustness of some of the results, particularly those regarding the effect of age and training on practitioner knowledge and behaviour.

In conclusion, the advice offered to preschool practitioners about how to boost children's language and communicative development is remarkably 
consistent across training manuals, and it is, in the main, well supported by the research literature. Practitioners retain the knowledge they have been taught, both about how children learn and about how to promote this learning. This knowledge translates into better practice, in that trained practitioners use some behaviours more often when interacting with children. However, the translation of some techniques into overt behaviour (e.g. turn-taking, adapting to the child's developmental level) could be more effective. In addition, we have found evidence for the effectiveness of the LC model in which at least one practitioner in a centre receives intensive training in language and communicative development and acts as an expertise hub for that centre.

\section{Acknowledgements}

We thank Sefton Local Authority School Readiness Team and all the centres, practitioners and children who took part.

\section{Funding}

The authors disclosed receipt of the following financial support for the research, authorship and/or publication of this article: The second author was supported by the International Centre for Language and Communicative Development at the University of Liverpool (LuCiD). The support of the Economic and Social Research Council (ES/1008955/1) is gratefully acknowledged.

\section{Notes}

1. Since these data were collected, a smaller 17-item version of the SPEAK II has been published (Suskind et al., 2017)

2. Levene's test was significant, so statistics for equal variances are not assumed.

\section{References}

Akhtar N (1999) Acquiring basic word order: Evidence for data-driven learning of syntactic structure. Journal of Child Language 26(2): 339-356.

Barnes S, Gutfreund M, Satterly D, et al. (1983) Characteristics of adult speech which predict children's language development. Journal of Child Language 10(1): 65-84.

Beck IL, McKeown MG and Kucan L (2013) Bringing Words to Life: Robust Vocabulary for Instruction. New York: Guilford Press.

Bercow J (2008) The Bercow Report: A Review of Services for Children and Young People (0-19) with Speech, Language and Communication Needs. Nottingham: DCSF.

Bettinghaus EP (1986) Health promotion and the knowledge-attitude-behavior continuum. Preventive Medicine 15(5): 475-491.

Bishop DVM and Snowling MJ (2004) Developmental dyslexia and specific language impairment: Same or different? Psychological Bulletin 130(6): 858-886. 
Blanden J (2006) 'Bucking the trend': What enables those who are disadvantaged in childhood to succeed later in life? Pensions 31: 36.

Bond MA and Wasik BA (2009) Conversation stations: Promoting language development in young children. Early Childhood Education Journal 36(6): 467-473.

Bornstein MH, Haynes MO and Painter KM (1998) Sources of child vocabulary competence: A multivariate model. Journal of Child Language 25(2): 367-393.

Brown R (1973) A first language: The early stages. Cambridge, MA: Harvard University Press.

Bryant PE, Bradly L, MacLean M, et al. (1989) Nursery rhymes, phonological skills and reading. Journal of Child Language 16: 407-428.

Burchinal M, McCartney K, Steinberg L, et al. (2011) Examining the Black-White achievement gap among low-income children using the NICHD study of early child care and youth development. Child Development 82(5): 1404-1420.

Buysse V, Castro DC and Peisner-Feinberg E (2010) Effects of a professional development program on classroom practices and outcomes for Latino dual language learners. Early Childhood Research Quarterly 25(2): 194-206.

Cabell SQ, Justice LM, McGinty AS, et al. (2015) Teacher-child conversations in preschool classrooms: Contributions to children's vocabulary development. Early Childhood Research Quarterly 30(PA): 80-92.

Cabell SQ, Justice LM, Piasta SB, et al. (2011) The impact of teacher responsivity education on preschoolers' language and literacy skills. American Journal of SpeechLanguage Pathology 20(4): 315-330.

Cartmill E, Armstrong BF, Gleitman LR, et al. (2013) Quality of early parent input predicts child vocabulary 3 years later. Proceedings of the National Academy of Sciences 110(28): 11278-11283.

Choi S (2000) Caregiver input in English and Korean: Use of nouns and verbs in book-reading and toy-play contexts. Journal of Child Language 27(1): 69-96.

Cleave PL, Becker SD, Curran MK, et al. (2015) The efficacy of recasts in language intervention: A systematic review and meta-analysis. American Journal of Speech-Language Pathology 24(2): 237-255.

Clegg J, Hoiss C and Rutter M (1999) Life sentence. RCSLT Bulletin 571: 16-18.

Demir-Vegter S, Aarts R and Kurvers J (2014) Lexical richness in maternal input and vocabulary development of Turkish preschoolers in the Netherlands. Journal of Psycholinguistic Research 43(2): 149-165.

Dickinson DK, Freiberg JB and Barnes EM (2013) Why are so few interventions really effective?: A call for fine-grained research methodology. In: Neuman SB and Dickinson DK (eds) Handbook of Early Literacy Research. New York: Guilford Press, pp. 337-357.

Dickinson DK, Hofer KG, Barnes EM, et al. (2014) Examining teachers' language in head start classrooms from a systemic linguistics approach. Early Childhood Research Quarterly 29(3): 231-244. 
Dickinson DK and Porche MV (2011) Relation between language experiences in preschool classrooms and children's kindergarten and fourth-grade language and reading abilities. Child Development 82(3): 870-886.

Dunham PJ, Dunham F and Curwin A (1993) Joint-attentional states and lexical acquisition at 18 months. Developmental Psychology 29(5): 827-831.

Dunst CJ, Meter D and Hamby DW (2011) Relationship between young children's nursery rhyme experiences and knowledge and phonological and print-related abilities. CELL Papers 4(1): 1-12.

Early DM, Maxwell KL, Ponder BD, et al. (2017) Improving teacher-child interactions: A randomized controlled trial of Making the Most of Classroom Interactions and My Teaching Partner professional development models. Early Childhood Research Quarterly 38: 57-70.

Eccles MP, Grimshaw JM, MacLennan G, et al. (2012) Explaining clinical behaviors using multiple theoretical models. Implementation Science 7(1): 99.

Fenson L, Marchman VA, Thal DJ, et al. (2006) The MacArthur-Bates Communicative Development Inventories User's Guide and Technical Manual, 2nd ed. Baltimore, MD: Brookes Publishing Co.

Gest SD, Holland-Coviello R, Welsh JA, et al. (2006) Language development subcontexts in head start classrooms: Distinctive patterns of teacher talk during free play, mealtime, and book reading. Early Education \& Development 17(2): 293-315.

Girolametto L, Weitzman E and Greenberg J (2003) Training day care staff to facilitate children's language. American Journal of Speech-Language Pathology 12(3): 299-311.

Goddard M, Durkin K and Rutter DR (1985) The semantic focus of maternal speech: A comment on Ninio and Bruner (1978). Journal of Child Language 12(1): 209-213.

Hamre BK, Pianta RC, Burchinal M, et al. (2012) A course on effective teacher-child interactions: Effects on teacher beliefs, knowledge, and observed practice. American Educational Research Journal 49(1): 88-123.

Hart B and Risley TR (1995) Meaningful Differences in the Everyday Experiences of Young American Children. Baltimore, MD: Brookes Publishing Co.

Hillman J and Williams T (2015) Early Years Education and Childcare: Lessons from Evidence and Future Priorities. London: Nuffield Foundation.

Hoff E (2003) Causes and consequences of SES-related differences in parent-to-child speech. In: Bornstein MH (ed.) Socioeconomic Status, Parenting, and Child Development. Mahwah, NJ: Erlbaum, pp. 147-160.

Hoff E (2006) How social contexts support and shape language development. Developmental Review 26: 55-88.

Hoff E and Naigles L (2002) How children use input to acquire a lexicon. Child Development 73(2): 418.

Hoff-Ginsberg E (1985) Some contributions of mothers' speech to their children's syntactic growth. Journal of Child Language 12(2): 367-385.

Hoff-Ginsberg E (1986) Function and structure in maternal speech: Their relation to the child's development of syntax. Developmental Psychology 22(2): 155-163. 
Hoff-Ginsberg E (1991) Mother-child conversation in different social classes and communicative settings. Child Development 62(4): 782-796.

Hoff-Ginsberg E and Shatz M (1982) Linguistic input and the child's acquisition of language. Psychological Bulletin 92(1): 3-26.

Houston-Price C, Mather E and Sakkalou E (2007) Discrepancy between parental reports of infants' receptive vocabulary and infants' behaviour in a preferential looking task. Journal of Child Language 34(4): 701-724.

Hurtado N, Marchman VA and Fernald A (2008) Does input influence uptake? Links between maternal talk, processing speed and vocabulary size in Spanish-learning children. Developmental Science 11(6): F31-F39.

Huttenlocher J, Vasilyeva M, Cymerman E, et al. (2002) Language input and child syntax. Cognitive Psychology 45(3): 337-374.

Huttenlocher J, Waterfall H, Vasilyeva M, et al. (2010) Sources of variability in children's language growth. Cognitive Psychology 61: 343-365.

Jones CP and Adamson LB (1987) Language use in mother-child and mother-childsibling interactions. Child Development 58(2): 356.

Landry SH, Swank PR, Anthony JL, et al. (2011) An experimental study evaluating professional development activities within a state funded pre-kindergarten program. Reading and Writing 24(8): 971-1010.

Lieven EVM. Crosslinguistic and crosscultural aspects of language addressed to children. In Gallaway C and Richards BJ (eds) Input and interaction in language acquisition. New York, NY: Cambridge University Press, pp. 56-73.

Lonigan CJ, Anthony JL, Bloomfield BG, et al. (1999) Effects of two shared-reading interventions on emergent literacy skills of at-risk preschoolers. Journal of Early Intervention 22(4): 306-322.

McGillion ML, Herbert JS, Pine JM, et al. (2013) Supporting early vocabulary development: What sort of responsiveness matters. IEEE Transactions on Autonomous Mental Development 5(3): 240-248.

MacWhinney B (2000) The CHILDES Project: Tools for Analyzing Talk. Mahwah, NJ: Lawrence Erlbaum Associates.

Markussen-Brown J, Juhl CB, Piasta SB, et al. (2017) The effects of language- and literacy-focused professional development on early educators and children: A bestevidence meta-analysis. Early Childhood Research Quarterly 38: 97-115.

Marteau TM and Lerman C (2001) Genetic risk and behavioural change. British Medical Journal (Clinical Research Ed.) 322(7293): 1056-1059.

Nelson K, Carskaddon G and Bonvillian J (1973) Syntax acquisition: Impact of experimental variation in adult verbal interaction with the child. Child Development 44(3): 497-504.

Newport E, Gleitman H and Gleitman L (1977) Mother, I'd rather do it myself: Some effects and non-effects of maternal speech style. In: Snow CE and Ferguson CF (eds) Talking to Children: Language Input and Interaction. Cambridge: Cambridge University Press, pp.109-150. 
Nicholas H, Lightbown PM and Spada N (2001) Recasts as feedback to language learners. Language Learning 51(4): 719-758.

Payne AC, Whitehurst GJ and Angell AL (1994) The role of home literacy environment in the development of language ability in preschool children from lowincome families. Early Childhood Research Quarterly 9(3-4): 427-440.

Pelatti CY, Piasta SB, Justice LM, et al. (2014) Language- and literacy-learning opportunities in early childhood classrooms: Children's typical experiences and withinclassroom variability. Early Childhood Research Quarterly 29(4): 445-456.

Phillips BM, Ingrole SA, Burris PW, et al. (2017) Investigating predictors of fidelity of implementation for a preschool vocabulary and language curriculum. Early Child Development and Care 187(3-4): 542-553.

Pianta RC, La Paro KM and Hamre BK (2008) Classroom Assessment Scoring System Manual, Pre-k. Baltimore, MD: Paul H. Brookes.

Pianta RC, La Paro KM, Payne C, et al. (2002) The relation of kindergarten classroom environment to teacher, family, and school characteristics and child outcomes. The Elementary School Journal 102(3): 225-238.

Piasta SB, Justice LM, Cabell SQ, et al. (2012) Impact of professional development on preschool teachers' conversational responsivity and children's linguistic productivity and complexity. Early Childhood Research Quarterly 27(3): 387-400.

Piasta SB, Justice LM, O’Connell AA, et al. (2017) Effectiveness of large-scale, statesponsored language and literacy professional development on early childhood educator outcomes. Journal of Research on Educational Effectiveness 10(2): 354-378.

Powell DR, Diamond KE, Burchinal MR, et al. (2010) Effects of an early literacy professional development intervention on Head Start teachers and children. Journal of Educational Psychology 102(2): 299-312.

Rowe ML (2012) A longitudinal investigation of the role of quantity and quality of child-directed speech in vocabulary development. Child Development 83(5): 1762-1774.

Rowland C (2014) Understanding Child Language Acquisition. Abingdon: Routledge.

Scarborough H and Dobrich W (1994) On the efficacy of reading to preschoolers. Developmental Review 14(3): 245-302.

Snow CE, Arlman-Rupp A, Hassing Y, et al. (1976) Mothers' speech in three social classes. Journal of Psycholinguistic Research 5(1): 1-20.

Suskind D, Leffel KR, Graf E, et al. (n.d.) The SPEAK: The survey of parental/providers' expectations and knowledge of early childhood cognitive and language development. Unpublished manuscript, University of Chicago.

Suskind DL, Leffel KR, Graf E, et al. (2016) A parent-directed language intervention for children of low socioeconomic status: A randomized controlled pilot study. Journal of Child Language 43(2): 366-406.

Suskind DL, Leung CYY, Webber RJ, et al. (2017) Development of the Survey of Parent/Provider Expectations and Knowledge (SPEAK). First Language 38(3): 1-20.

Tamis-LeMonda CS, Bornstein MH and Baumwell L (2001) Maternal responsiveness and children's achievement of language milestones. Child Development 72(3): 748-767. 
Tamis-LeMonda CS, Bornstein MH, Baumwell L, et al. (1996) Responsive parenting in the second year: Specific influences on children's language and play. Early Development and Parenting 5(5): 173-183.

Tamis-LeMonda CS, Bornstein MH, Kahana-Kalman R, et al. (1998) Predicting variation in the timing of language milestones in the second year: An events history approach. Journal of Child Language 25(3): 675-700.

Tomasello M and Farrar MJ (1986) Joint attention and early language. Child Development $57(6)$ : 1454-1463.

Tomlinson CA (1999) Mapping a route toward a differentiated instruction. Educational Leadership 57(1): 12 .

Tomlinson CA, Brighton C, Hertberg H, et al. (2003) Differentiating instruction in response to student readiness, interest, and learning profile in academically diverse classrooms: A review of literature. Journal for the Education of the Gifted 27(2/3): 119-145.

U.S. Department of Education. (2001) The Longitudinal Evaluation of School Change and Performance (LESCP) in Title I Schools. Washington, DC: Author.

Vibbert $\mathrm{M}$ and Bornstein MH (1989) Specific associations between domains of mother-child interaction and toddler referential language and pretense play. Infant Behavior and Development 12(2): 163-184.

Waldfogel J and Washbrook E (2010) Low Income and Early Cognitive Development in the UK: A Report for the Sutton Trust. London: The Sutton Trust.

Walls HL, Peeters A, Loff B, et al. (2009) Why education and choice won't solve the obesity problem. American Journal of Public Health 99(4): 590-592.

Wasik BA and Hindman AH (2011) Improving vocabulary and pre-literacy skills of at-risk preschoolers through teacher professional development. Journal of Educational Psychology 103(2): 455-469.

Wasik BA and Hindman AH (2014) Understanding the active ingredients in an effective preschool vocabulary intervention: An exploratory study of teacher and child talk during book reading. Early Education and Development 25(7): 1035-1056.

Weizman ZO and Snow CE (2001) Lexical input as related to children's vocabulary acquisition: Effects of sophisticated exposure and support for meaning. Developmental Psychology 37(2): 265-279.

Whorrall J and Cabell SQ (2016) Supporting children's oral language development in the preschool classroom. Early Childhood Education Journal 44(4): 335-341.

Wiig EH, Secord WA and Semel E (2006) Clinical Evaluation of Language Fundamentals - UK, 2nd ed. London: Harcourt Assessment.

Williamson JML and Martin AG (2010) Analysis of patient information leaflets provided by a district general hospital by the Flesch and Flesch-Kincaid method. International Journal of Clinical Practice 64(13): 1824-1831. 